\title{
Pulsed Electrical Discharges Assisted by Dielectric Pellets /Catalysts for Diesel Engine Exhaust Treatment
}

\author{
B. S. Rajanikanth and V. Ravi \\ Dept. of High Voltage Engineering \\ Indian Institute of Science \\ Bangalore 560012, India
}

\begin{abstract}
This paper reports the study on gaseous pollutants (NOx, CO and HC's) using a combination of electric discharge plasma and catalysts. In this study, catalysts being used in conventional catalytic converters of gasoline engine were tried, for the first time, in diesel engine exhaust treatment assisted by electric discharge plasma. Initial studies investigate the effect of packed dielectric materials and catalysts on NOx removal. Both conventional and non-conventional catalysts were used in the studies. With plasma alone, the removal efficiency of oxides of nitrogen was around $75 \%$ and with a suitable combination of catalytic reactor the removal efficiency was as high as $\mathbf{9 0 \%}$. Among the catalysts studied, a new catalyst $\left(\mathrm{CuMnAlO}{ }_{4}\right)$ was found to be as effective as the conventional expensive catalyst. The formation of byproducts like $\mathrm{N}_{2} \mathrm{O}$ and $\mathrm{HNO}_{3}$ have been studied and the results are discussed.
\end{abstract}

\section{INTRODUCTION}

$V^{-1}$ EHICULAR pollution is a serious problem today. Due to increased growth in vehicular traffic, the progress achieved through existing control devices are getting offset. The problem is more serious when it comes to diesel engines. The problem with the conventional after treatment technique such as a three-way catalytic converter, which has proved to be very successful in gasoline engines, cannot be applied to lean burn spark ignition engines or diesel engines because these engines burn their fuel with a high excess of air and the oxygen in the exhaust gas stream prevents the catalytic decomposition of oxides of nitrogen. In addition, the precious metals used in the conventional catalytic converters are highly expensive and originate from limited natural sources. This has led the researchers to look for alternative measures for the removal of NOx resulting in the emergence of nonthermal plasma as a technique for gas treatment. Nonthermal plasma associated with electrical discharges is an excellent technique for the removal of oxides of nitrogen and is proved to be cost effective [1-5]. Non-thermal plasma alone will not be able to remove all the major pollutants present in the automobile exhaust. However, when the discharge plasma is combined with catalysts, there is a scope for removal of these pollutants.

Recently there have been some efforts by researchers in combining catalysts with electric discharge plasma [6-11] but none of these studies was performed using actual

Manuscript received on 5 October 2001, in final form 7 May 2002. diesel engine exhaust. Since actual exhaust consists of multitude components, the simulated exhaust may provide an incomplete picture of the processes involved. The reactions taking place during the treatment of actual exhaust by pulsed discharges vary largely from that of the simulated exhaust. The investigations of a pulsed corona reactor for treating heavy-duty diesel engine emissions by Grothaus and Fanick [12] resulted in 60\% NOx removal efficiency. Although oxidizing reactions are more pronounced in the case of diesel exhaust (which lead to the formation of $\mathrm{NO}_{2}$ and $\mathrm{HNO}_{3}$ ), there was still a marked decrease in total NOx. The same authors have also studied the effect of combination of pulsed corona discharges and catalysts and reported NOx removal efficiency of about $70 \%$ [13]. They have not made known the type of catalysts used.

The present work intends to study the feasibility of combining electric discharge plasma with conventional/ non-conventional catalysts for treating diesel engine exhaust. The diesel engine was operated under no load condition. Though main emphasis was given to the NOx removal, the concentrations of $\mathrm{CO}$ and HC's were also monitored simultaneously. Initial studies include the effect of packed dielectric materials and catalysts in a plasma reactor on NOx removal. Studies were conducted at different temperatures. The formation of main byproducts associated with NOx removal is also discussed briefly.

\section{EXPERIMENTAL SETUP}

Figure 1 shows the experimental setup. The pulse source consists of a single-phase ac supply, Cockraft-Walton dc 


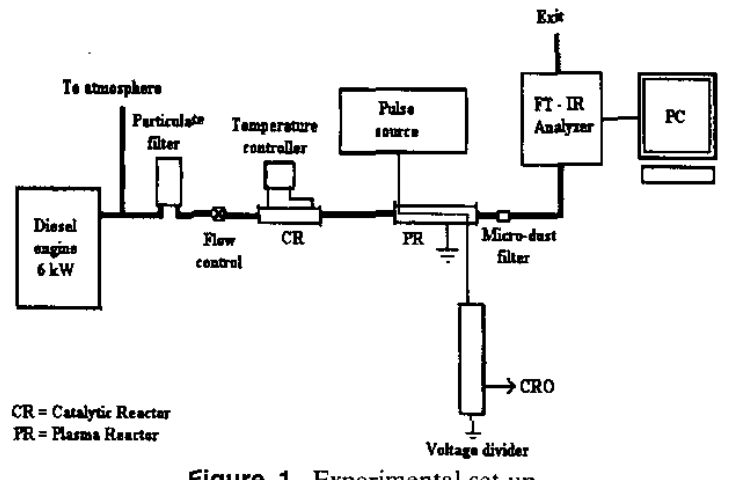

Figure 1. Experimental set up.

voltage multiplier circuit and a rotary spark gap (RSG). The hemispherical rotating electrode of the RSG was connected to a motor through an insulating rod. By changing the speed of the motor, the frequency of the pulses applied to the reactor can be controlled. Throughout the experiments the frequency of the pulses was kept constant at 100 pps (pulses per second). The pulse voltage applied to the reactor was measured by means of a $150 \mathrm{MHz}$ digital oscilloscope (DL1540, 200MS/s Yokogawa) connected through a 2000:1 voltage divider (EP-50K, $50 \mathrm{MHz}$, Peec, Japan). The power was measured directly from the oscilloscope as the product of voltage and current waveforms. The specific energy density in Joules per liter was then calculated as the ratio of power (W) to the flow rate (liter per minute). A $6 \mathrm{~kW}$ diesel engine, under no load conditions, was used for the experiments. A part of the exhaust gas was made to pass through a particulate filter first (PROGARD ${ }^{\mathrm{TM}}$, Millipore India Ltd.) to filter out solid particulates down to 4 microns in diameter and then fed to the reactors. A flow meter connected after the particulate filter was adjusted to get a constant gas flow rate of 0.75 liter per minute $(\mathrm{lpm})$. The measurement of NOx from the diesel exhaust was done using an FTIR gas analyzer (DX-4010, Temet Instruments, Finland). Before feeding the exhaust gas into the analyzer, the gas was made to pass through a micro-dust filter to filter out particulates down to $2 \mu \mathrm{m}$. The GASMET ${ }^{\mathrm{TM}}$ uses the CALCMET ${ }^{\mathrm{TM}}$ software to compute the concentrations of the components present in the sample gas from the absorbance spectrum.

During the course of experiments, two different reactors were used, specifically the plasma reactor $(P R)$ and the catalytic reactor (CR). The $P R$ is a dielectric barrier discharge reactor made up of quartz glass tube of diameter (inner diameter $=15 \mathrm{~mm}$ and outer diameter $=17$ $\mathrm{mm}$ ). It consists of a stainless steel wire of $0.1 \mathrm{~mm}$ diameter as the inner electrode and aluminum foil wrapped over the quartz glass tube as the outer electrode. The studies were conducted by filling the PR successively with dielectric pellets and then with catalysts. Figure $2 a$ shows plasma reactor without pellets and Figure $2 \mathrm{~b}$ shows the PR filled

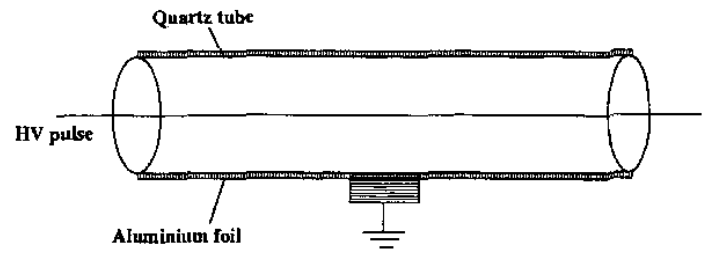

(a)

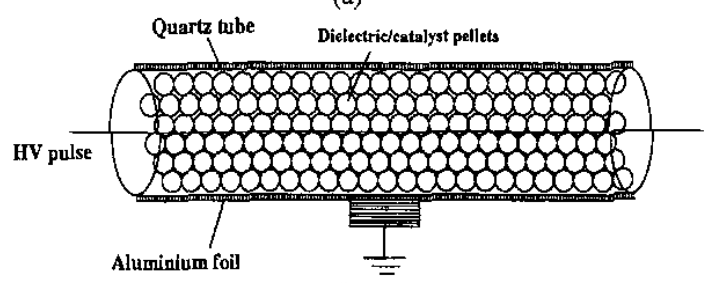

(b)

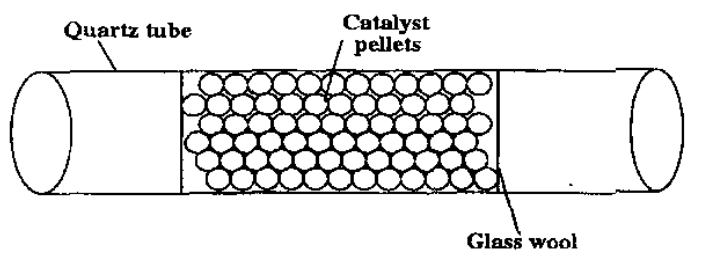

(c) .

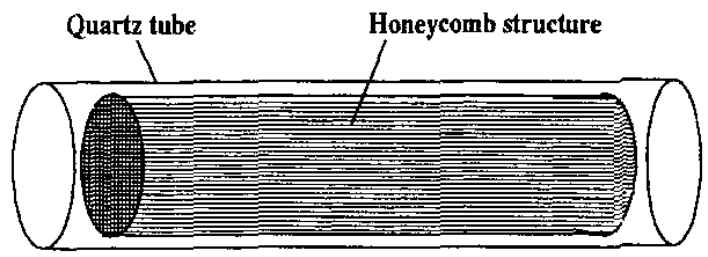

(d)

Figure 2. a, reactor without pellets; b, reactor filled with dielectric/catalyst pellets; c, reactor filled with catalyst pellets; d, reactor filled with honeycomb catalyst.

with dielectric pellets/catalysts. In the present experiments dielectric pellets such as $\mathrm{BaTiO}_{3}\left(\epsilon_{r}=3200\right), \mathrm{Al}_{2} \mathrm{O}_{3}$ $\left(\epsilon_{r}=10\right)$ and glass beads $\left(\epsilon_{r}=10\right)$ were used. The experiments were then conducted by replacing the dielectric pellets with catalysts such as $\mathrm{Pd} / \mathrm{Al}_{2} \mathrm{O}_{3}, \mathrm{CuO}$ and $\mathrm{Fe}_{2} \mathrm{O}_{3}$.

The catalytic reactors consisted of a pellet bed reactor and a honeycomb reactor. Figure $2 \mathrm{c}$ shows the catalytic reactor (glass tube of $15 \mathrm{~mm}$ diameter and $300 \mathrm{~mm}$ length) filled with catalyst pellets such as $\mathrm{Pd} / \mathrm{Al}_{2} \mathrm{O}_{3}$ and $\mathrm{Fe}_{2} \mathrm{O}_{3}$. The catalysts are packed inside the reactor for a length of about $70 \mathrm{~mm}$ and both the ends were held by glass wool. Figure $2 \mathrm{~d}$ shows the catalytic reactor filled with a honeycomb structure coated with a conventional catalyst (Pt$\mathrm{Rh} / \mathrm{CeO}_{2}-\mathrm{Al}_{2} \mathrm{O}_{3}$ ) and a non-conventional catalyst $(\mathrm{CuMnAlO})_{4}$. The honeycomb for the former is of length $120 \mathrm{~mm}$ and diameter $25 \mathrm{~mm}$ and was inserted in a glass tube ( $30 \mathrm{~mm}$ diameter, $300 \mathrm{~mm}$ long), while for the latter the honeycomb is of length $120 \mathrm{~mm}$ and diameter $12 \mathrm{~mm}$ and was inserted in a glass tube $(15 \mathrm{~mm}$ diameter, $300 \mathrm{~mm}$ long). In both cases the CR was kept inside an electric 
furnace. A brief explanation of the catalysts used in the experiments is given below.

1. $\mathrm{Pd} / \mathrm{Al}_{2} \mathrm{O}_{3}$ (palladium coated over alumina). This is the most commonly used conventional two-way oxidation catalyst for exhaust gas treatment. This was used in the form of pellets ( $5 \mathrm{~mm}$ long and $3 \mathrm{~mm}$ diameter). The catalyst is active at $\leq 200^{\circ} \mathrm{C}$.

2. $\mathrm{CuO}-\mathrm{ZnO}-\mathrm{Al}_{2} \mathrm{O}_{3}$ (copper oxide coated over a support of zinc oxide and alumina). This is a base metal catalyst. Before the advent of noble metal catalysts these catalysts were initially used to treat the exhaust gas emissions. Pellets with size of $4 \mathrm{~mm}$ long and $6 \mathrm{~mm}$ diameter were used in the present studies. This is a good oxidation catalyst for the oxidation reactions of $\mathrm{CO}$ and HCs. The catalyst is active in a narrow temperature window of $200-300^{\circ} \mathrm{C}$.

3. $\mathrm{Fe}_{2} \mathrm{O}_{3}-\mathrm{Cr}_{2} \mathrm{O}_{3}$ (Iron oxide doped with chromia). This is also a base metal catalyst that was used in the treatment of exhaust gas before the advent of noble metal catalysts. Pellets with $4 \mathrm{~mm}$ long and $6 \mathrm{~mm}$ diameter were used in the present studies. The oxidation reactions start around $200^{\circ} \mathrm{C}$ with this catalyst and the catalyst loses its activity above $500^{\circ} \mathrm{C}$.

4. Pt-Rh/ $\mathrm{CeO}_{2}-\mathrm{Al}_{2} \mathrm{O}_{3}$ (platinum and rhodium coated over a support of ceria and alumina). This is the most commonly used conventional three-way catalyst for the auto exhaust treatment. This catalyst is coated on a cordierite honeycomb structure of length $120 \mathrm{~mm}$ and diameter $25 \mathrm{~mm}$. The catalyst is active at $>200^{\circ} \mathrm{C}$.

5. CuMnAlO . This is a new catalyst prepared in the laboratory. It is a non-conventional catalyst, coated on a cordierite honeycomb structure of length $120 \mathrm{~mm}$ and diameter $12 \mathrm{~mm}$. This is a very good oxidation catalyst and works at $>175^{\circ} \mathrm{C}$.

\section{RESULTS AND DISCUSSION}

A diesel engine of $6 \mathrm{~kW}$ under no load conditions was setup in the laboratory. The experiments were conducted using a filtered exhaust gas. Only a portion of the filtered exhaust gas from the diesel engine was passed through the reactors. Before treating the exhaust gas, either with the $\mathrm{PR}$ and/or the CR, the concentrations of CO, THC, NOx, $\mathrm{N}_{2} \mathrm{O}, \mathrm{H}_{2} \mathrm{O}$, and $\mathrm{CO}_{2}$ were measured using a FTIR multicomponent gas analyzer. Also, the concentration of oxy-

Table 1. Initial concentrations of diesel engine exhaust gas components.

\begin{tabular}{ll}
\hline \multicolumn{1}{c}{ Component } & \multicolumn{1}{c}{ Concentration } \\
\hline $\mathrm{CO}$ & $700 \mathrm{ppm}$ \\
$\mathrm{THC}$ & $90 \mathrm{ppm}$ \\
$\mathrm{NOx}\left(\mathrm{NO}+\mathrm{NO}_{2}\right)$ & $150(115+35) \mathrm{ppm}$ \\
$\mathrm{N}_{2} \mathrm{O}$ & $2.5 \mathrm{ppm}$ \\
$\mathrm{H}_{2} \mathrm{O}$ & $2.5 \mathrm{vol} \%$ \\
$\mathrm{CO}_{2}$ & $2 \mathrm{vol} \%$ \\
$\mathrm{O}_{2}$ & $11.2 \mathrm{vol} \%$ \\
\hline
\end{tabular}

gen present in the diesel exhaust was measured using a NDIR gas analyzer. Table 1 shows the initial concentrations of these components present in the diesel engine exhaust gas. In the table, "NOx" means the sum of NO and $\mathrm{NO}_{2}$ concentrations. The concentrations of $\mathrm{NO}$ and $\mathrm{NO}_{2}$ were measured individually and then added to get the NOx concentration. The total hydrocarbons (THC) are the sum of various HC's present in the exhaust. THC in the present study includes methane $\left(\mathrm{CH}_{4}\right)$, ethylene $\left(\mathrm{C}_{2} \mathrm{H}_{4}\right)$, acetylene $\left(\mathrm{C}_{2} \mathrm{H}_{2}\right)$, butane $\left(\mathrm{C}_{4} \mathrm{H}_{10}\right)$, propene $\left(\mathrm{C}_{3} \mathrm{H}_{6}\right)$, benzene $\left(\mathrm{C}_{6} \mathrm{H}_{6}\right)$, and toluene $\left(\mathrm{C}_{7} \mathrm{H}_{8}\right)$. The experiments were conducted for three arrangements of the plasma reactors as shown below.

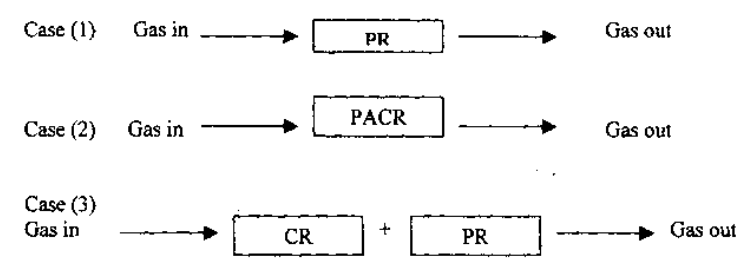

PACR refers to plasma-assisted catalytic reactor. In each of the above cases, the relevant exhaust gas component concentrations were measured before and after the plasma/catalytic treatment. In all the experiments, the PR was kept at room temperature and the temperature of the $\mathrm{CR}$ alone was varied from room temperature to $300^{\circ} \mathrm{C}$.

\subsection{STUDIES USING PLASMA REACTOR}

(PR)

The effect of dielectric pellets on NOx removal has been investigated $[14,15]$ and it was found that the efficiency of the plasma reactor increased by packing it with dielectric pellets. When the plasma reactor was filled with dielectric pellets and pulsed high voltage was applied across the pellet bed, the pellets become polarized and an intense electric field is formed around the contact points of each pellet, causing partial discharges between the pellets. This partial discharge together with the discharge from the wire (referred to as combined discharge) helps in increasing the radical production thereby enhancing the chemical reaction rates leading to more NO removal. However, none of these investigations was conducted on actual diesel engine exhaust. Experiments on NOx removal using dielectric pellets have been conducted to verify the above fact using actual diesel engine exhaust. In these studies the exhaust was treated using a plasma reactor packed with different dielectric materials ( $\mathrm{BaTiO}_{3}, \mathrm{Al}_{2} \mathrm{O}_{3}$ and glass beads). Experiments were also conducted without using any pellets. The study is intended to determine the relative performance of various dielectric pellets. All the experiments were conducted at room temperature. Figure $3 \mathrm{a}$ shows the NOx removal efficiency using PR packed with dielectric pellets and PR without pellets as function of specific en- 


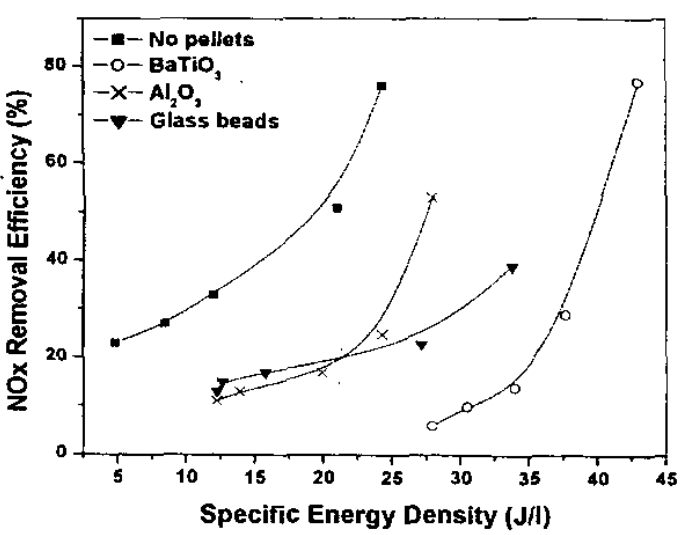

(a)

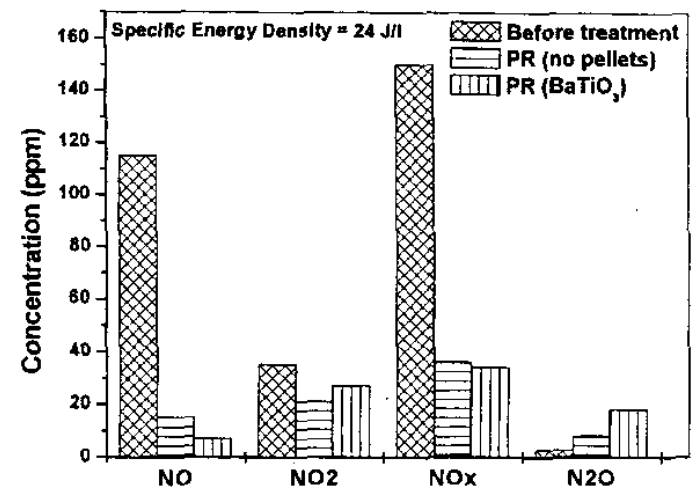

(b)

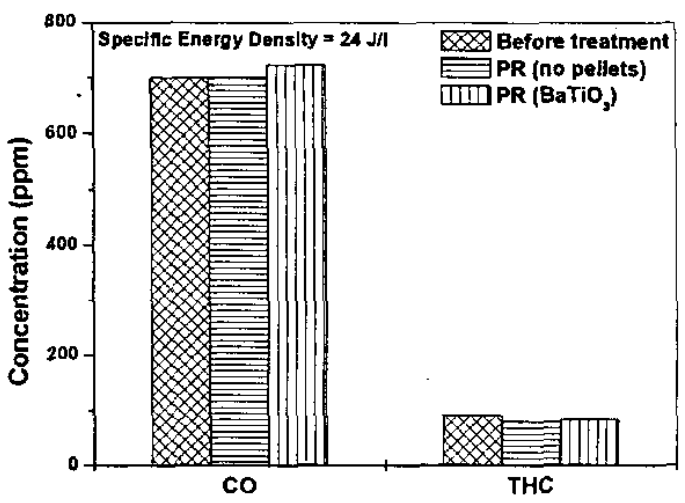

(c)

Figure 3. a, NOx removal efficiency for PR packed with and without dielectric pellets as a function of specific energy density; $b$, comparison of concentrations of $\mathrm{NO}, \mathrm{NO}_{2}, \mathrm{NOx}$ and $\mathrm{N}_{2} \mathrm{O}$ for $\mathrm{PR}$ packed with $\mathrm{BaTiO}_{3}$ and $\mathrm{PR}$ without pellets; $\mathrm{c}$, comparison of concentrations of $\mathrm{CO}$ and $\mathrm{THC}$ for PR packed with $\mathrm{BaTiO}_{3}$ and $\mathrm{PR}$ without pellets.

ergy density. Both $\mathrm{BaTiO}_{3}$ packed $\mathrm{PR}$ and $\mathrm{PR}$ without pellets show maximum NOx removal efficiency. PR packed with $\mathrm{Al}_{2} \mathrm{O}_{3}$ and glass beads exhibited high $\mathrm{NO}$ removal but not NOx removal. Also, it should be noted that the PR without pellets exhibited the least energy consump- tion. Figure $3 b$ compares the concentrations of $\mathrm{NO}, \mathrm{NO}_{2}$, $\mathrm{NOx}$ and $\mathrm{N}_{2} \mathrm{O}$ for PR packed with $\mathrm{BaTiO}_{3}$ and PR without pellets, before and after treatment, at the maximum specific energy density. It is observed that the reduction in $\mathrm{NOx}$ is almost the same for both cases. With $\mathrm{BaTiO}_{3}$ packed $\mathrm{PR}$, the $\mathrm{NO}_{2}$ production is higher compared to - PR without pellets, which indicates that $\mathrm{BaTiO}_{3}$ generates maximum quantity of oxygen species. Consequently, $\mathrm{BaTiO}_{3}$ packed $\mathrm{PR}$ generated maximum amount of $\mathrm{N}_{2} \mathrm{O}$ as compared to $\mathrm{PR}$ without pellets. At maximum specific energy density $(24 \mathrm{~J} / \mathrm{l})$ the concentration of $\mathrm{N}_{2} \mathrm{O}$ increased to $18 \mathrm{ppm}$ from an initial value of $2.5 \mathrm{ppm}$ for $\mathrm{BaTiO}_{3}$ packed PR. For PR without pellets the concentration of $\mathrm{N}_{2} \mathrm{O}$ was increased to $8 \mathrm{ppm}$ from an initial value of $2.5 \mathrm{ppm}$. Figure $3 \mathrm{c}$ compares the concentrations of $\mathrm{CO}$ and $\mathrm{THC}$ for $\mathrm{BaTiO}_{3}$ packed $\mathrm{PR}$ and $\mathrm{PR}$ without pellets before and after treatment at the maximum specific energy density. For $\mathrm{BaTiO}_{3}$ packed PR the concentration of $\mathrm{CO}$ was found to increase from the initial value. At maximum specific energy density, the $\mathrm{CO}$ concentration was increased to $725 \mathrm{ppm}$ from an initial value of 700 ppm whereas for PR without pellets there was no change in initial $\mathrm{CO}$ concentration. There is a slight reduction $(10 \%)$ in the concentration of $\mathrm{THC}$ using $\mathrm{BaTiO}_{3}$ packed PR and PR without pellets. From the above discussion, it is observed that PR without pellets is a better choice compared to PR filled with dielectric pellets. A detailed study of NOx removal using PR without pellets is explained in the following paragraph.

Figure 4a shows the removal efficiencies of NO and NOx for PR without pellets. When the specific energy density is around $5 \mathrm{~J} / 1$, the concentration of NO was decreased to $45 \mathrm{ppm}$ from an initial value of $115 \mathrm{ppm}$. This reduction corresponds to about $60 \%$ removal of NO. This is because of strong oxidation reaction in high oxygen atmosphere leading to the formation of $\mathrm{NO}_{2}$. The concentration of $\mathrm{NO}_{2}$ was increased to $70 \mathrm{ppm}$ from an initial value of 35 $\mathrm{ppm}$ at this specific energy density. So, there is a decrease in NOx concentration by $34 \mathrm{ppm}$ (from initial $150 \mathrm{ppm}$ to $116 \mathrm{ppm}$ ). But up to specific energy density of $13 \mathrm{~J} / \mathrm{l}$, the oxidation reactions were dominant resulting in NO removal efficiency of nearly $80 \%$ and NOx removal efficiency of only around $35 \%$. However, beyond $20 \mathrm{~J} / 1$, the concentration of $\mathrm{NO}_{2}$ started decreasing thereby increasing the removal efficiency of NOx. The reason for $\mathrm{NO}_{2}$ drop is that the $\mathrm{NO}_{2}$ reacts with hydrocarbons and water to release various other $\mathrm{HC}$ by-products, $\mathrm{HNO}_{3}, \mathrm{~N}_{2} \mathrm{O}$ etc. The rate coefficients for these reactions are more favorable at higher radical energies than that at lower radical energies. At $24 \mathrm{~J} / \mathrm{I}$ the NOx removal efficiency became $76 \%$. This is well represented in Figure $4 \mathrm{~b}$, which shows the concentrations of $\mathrm{NO}, \mathrm{NO}_{2}, \mathrm{NOx}$ and $\mathrm{N}_{2} \mathrm{O}$ as a function of specific energy density. It has been reported that without any additives the reduction of $\mathrm{NO}$ into $\mathrm{N}_{2}$ in high oxygen atmosphere is not possible $[14,17]$. In the present studies, since an actual diesel exhaust was treated, it is 


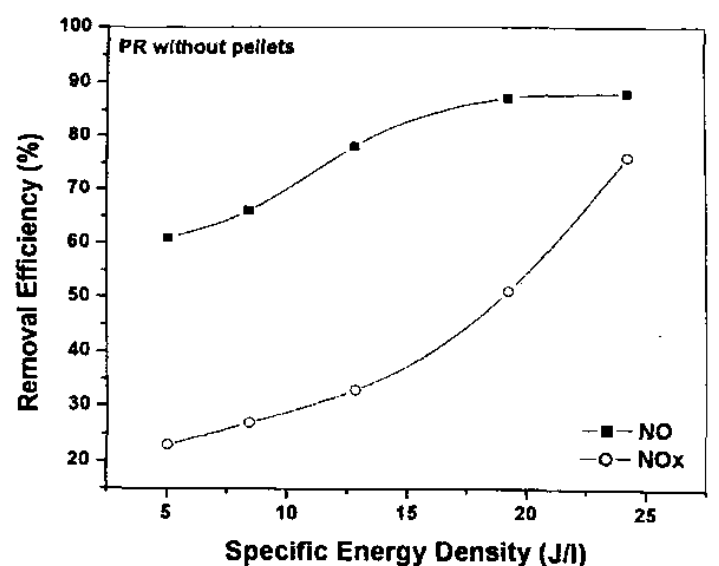

(a)

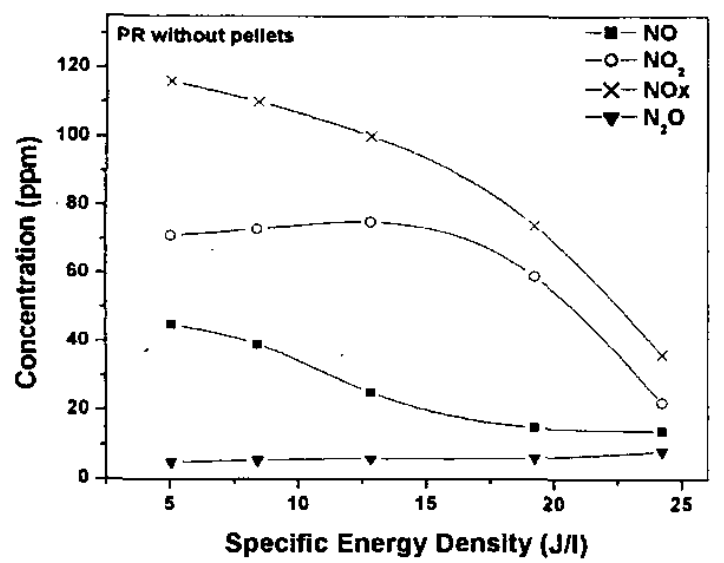

(b)

Figure 4. a, NO and NOx removal efficiencies for PR without pellets; $b$, concentrations of $\mathrm{NO}, \mathrm{NO}_{2}, \mathrm{NOx}$ and $\mathrm{N}_{2} \mathrm{O}$ as function of specific energy density for PR without pellets.

possible that the presence of $\mathrm{HCs}$ in the exhaust has played the role of additives in the decrease of NO concentration [12]. To correlate this we observed decrease in the concentration of hydrocarbons. At the same time the NOx removal was also associated with the formation of $\mathrm{HNO}_{3}$ and $\mathrm{N}_{2} \mathrm{O}$. The concentration of $\mathrm{N}_{2} \mathrm{O}$ was found to increase from initial $2.5 \mathrm{ppm}$ to $8 \mathrm{ppm}$ at the maximum specific energy density $(24 \mathrm{~J} / \mathrm{l})$. Though $\mathrm{HNO}_{3}$ was not measured quantitatively, its presence was confirmed by qualitative analysis. For this, the treated exhaust gas was made to pass through distilled water for about 10 minutes and this water was tested for its acidity using a $\mathrm{pH}$ meter. The results confirmed the presence of $\mathrm{HNO}_{3}$. The formation of $\mathrm{HNO}_{3}$ is desirable as it could easily be neutralized to a salt by simple chemical methods.

\subsection{STUDIES USING PLASMA-ASSISTED CATALYTIC REACTOR (PACR)}

The efficiency of NO removal achieved by a catalyst assisted with electric discharge plasma at room temperature has been reported [15] and found to be quite comparable with that achieved by conventional catalytic converters operated at $\leq 300^{\circ} \mathrm{C}$. However, the above study was not conducted by using actual diesel exhaust gas. Also, NOx removal was not discussed. Hence, the focus of this paper is placed on the NOx removal by catalysts assisted by electrical discharges using actual diesel engine exhaust gases and comparison of performances of conventional and non-conventional catalysts assisted by electrical discharges. The experiments were conducted by packing the catalysts (in pellet form) in a plasma reactor at room temperature using actual diesel engine exhaust. A reactor configured in this manner is referred to as a plasmaassisted catalytic reactor (PACR). The studies were limited to room temperature because of the practical difficulties. The catalysts used in the study were $\mathrm{Pd} / \mathrm{Al}_{2} \mathrm{O}_{3}$, (a conventional catalyst) and $\mathrm{Fe}_{2} \mathrm{O}_{3}$ and $\mathrm{CuO}$ (both nonconventional catalysts). Figure 5a shows the NOx removal efficiencies as function of specific energy density for PACR packed with different catalysts. It is observed that the NOx removal efficiency is above $60 \%$ for low specific energy densities in all cases. The NOx removal is dominated by catalytic adsorption rather than by pulsed discharges in these cases. $\mathrm{Fe}_{2} \mathrm{O}_{3}$ and $\mathrm{CuO}$ showed very high adsorption characteristics when compared to $\mathrm{Pd} / \mathrm{Al}_{2} \mathrm{O}_{3}$ catalysts. The NOx concentration was decreased from $150 \mathrm{ppm}$ to 105 ppm with $\mathrm{Pd} / \mathrm{Al}_{2} \mathrm{O}_{3}$ catalysts. This amounts to $30 \%$ removal of NOx. However, when the specific energy density is around $5 \mathrm{~J} / \mathrm{l}$ the NOx removal efficiency became $63 \%$. For higher specific energy densities, the removal was linear and reached a maximum of $88 \%$. With the $\mathrm{CuO}$ packed PACR, the NOx removal efficiency was almost saturated beyond a specific energy density of $5 \mathrm{~J} / 1$. CuO alone adsorbed nearly $70 \mathrm{ppm}$ NOx out of initial $150 \mathrm{ppm}$. The maximum NOx removal efficiency obtained with the $\mathrm{CuO}$ packed PACR was $94 \%$. For the $\mathrm{Fe}_{2} \mathrm{O}_{3}$ packed PACR, the NOx removal efficiency was $90 \%$ for a specific energy density of only $5 \mathrm{~J} / \mathrm{l}$. This is because $\mathrm{Fe}_{2} \mathrm{O}_{3}$ catalysts adsorbed $116 \mathrm{ppm}$ of NOx (77\% adsorption). Beyond this specific energy density, there was no significant increase in removal efficiency. Figure $5 \mathrm{~b}$ compares the concentrations of $\mathrm{NO}, \mathrm{NO}_{2}, \mathrm{NOx}$ and $\mathrm{N}_{2} \mathrm{O}$ before and after treatment for PACR packed with catalyst pellets. Though the NOx removal was higher for $\mathrm{CuO}$ and $\mathrm{Fe}_{2} \mathrm{O}_{3}$ packed $\mathrm{PACR}$, the $\mathrm{N}_{2} \mathrm{O}$ production was higher for these two when compared to $\mathrm{Pd} / \mathrm{Al}_{2} \mathrm{O}_{3}$ catalysts.

Figure $5 \mathrm{c}$ compares the concentrations of $\mathrm{CO}$ and THC before and after treatment for PACR packed with catalyst pellets at maximum specific energy density $(24 \mathrm{~J} / \mathrm{l})$. The $\mathrm{Fe}_{2} \mathrm{O}_{3}$ packed PACR showed maximum removal of $\mathrm{CO}$ followed by the $\mathrm{Pd} / \mathrm{Al}_{2} \mathrm{O}_{3}$ and $\mathrm{CuO}$ cases. The readings were taken by passing the exhaust gas through the catalyst until steady readings were obtained. Once the readings were stabilized (i.e. no more adsorption is possible by the catalysts) the discharges were produced inside the reactor by applying the pulses. It was found that the presence of 


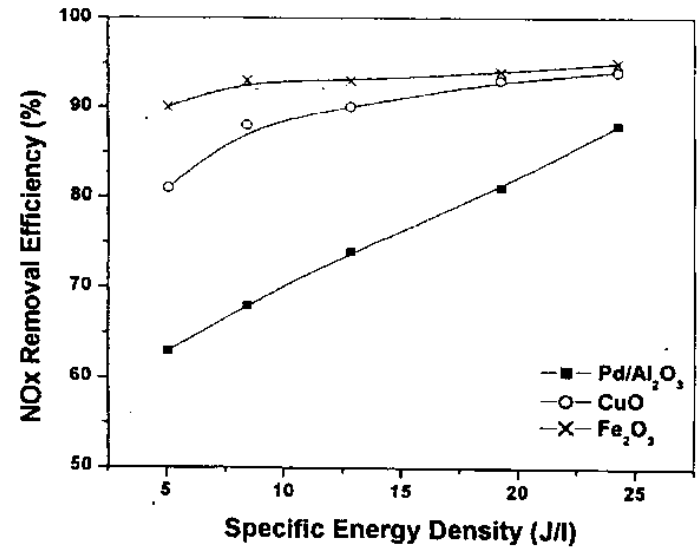

(a)

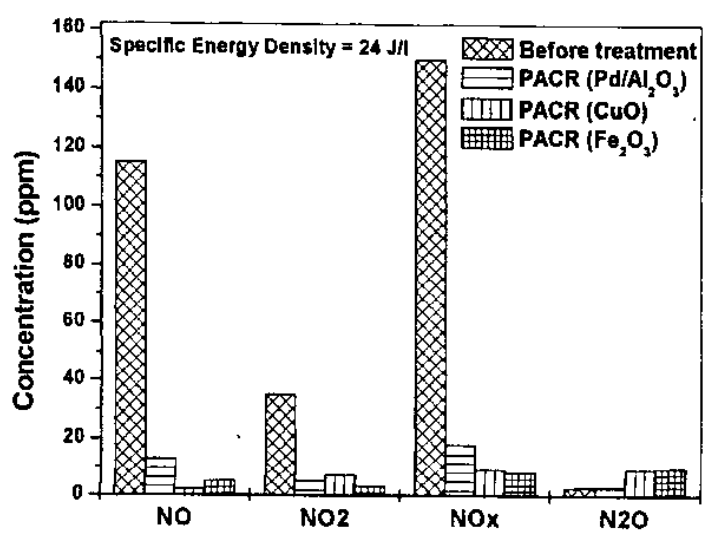

(b)

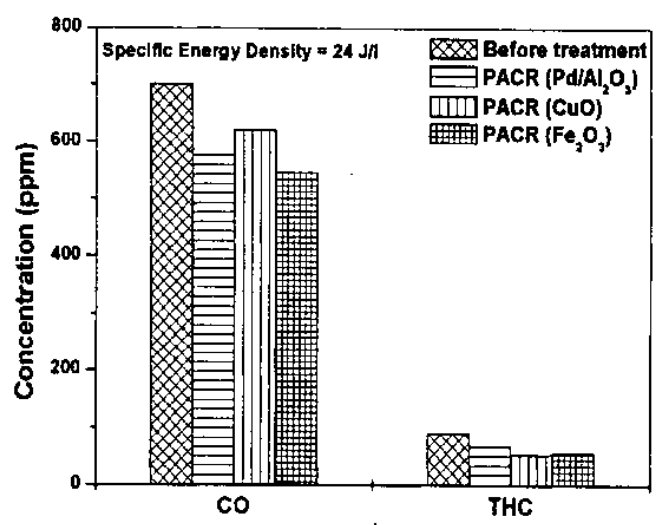

(c)

Figure 5. a, NOx removal efficiency for PACR packed with catalyst pellets; $b$, comparison of concentrations of $\mathrm{NO}, \mathrm{NO}_{2}, \mathrm{NOx}$ and $\mathrm{N}_{2} \mathrm{O}$ for PACR packed with catalyst pellets; $c$, comparison of concentrations of $\mathrm{CO}$ and THC for PACR packed with catalyst pellets.

discharges enhanced the $\mathrm{CO}$ removal by catalyst. The catalyst $\mathrm{Fe}_{2} \mathrm{O}_{3}$ alone removed $125 \mathrm{ppm}$ of $\mathrm{CO}$ (by adsorption process) and the combination of discharges and catalyst removed $155 \mathrm{ppm}$ of $\mathrm{CO}$. Hence $30 \mathrm{ppm}$ of $\mathrm{CO}$ was re-
Table 2. $\mathrm{CO}$ and $\mathrm{THC}$ removal efficiencies using different catalysts for PACR at $27^{\circ} \mathrm{C}$.

\begin{tabular}{cccc}
\hline & \multicolumn{3}{c}{ Removal Efficiencies (\%) } \\
\cline { 2 - 4 } Pollutants & ${\mathrm{Pd} / \mathrm{Al}_{2} \mathrm{O}_{3}}$ & $\mathrm{CuO}$ & $\mathrm{Fe}_{2} \mathrm{O}_{3}$ \\
\hline $\mathrm{CO}$ & 18 & 11 & 22 \\
$\mathrm{THC}$ & 26 & 42 & 39 \\
\hline
\end{tabular}

moved by the catalysts in presence of pulsed discharges. There was about $50 \mathrm{ppm}$ of $\mathrm{CO}$ adsorption using $\mathrm{Pd} / \mathrm{Al}_{2} \mathrm{O}_{3}$ catalysts. The PACR packed with $\mathrm{Pd} / \mathrm{Al}_{2} \mathrm{O}_{3}$ catalysts removed $125 \mathrm{ppm}$ of $\mathrm{CO}$. So, there was a decrease in $\mathrm{CO}$ concentration by $75 \mathrm{ppm}$ in the presence of pulsed discharges. Adsorption of $\mathrm{CO}$ by $\mathrm{CuO}$ was much less $(10 \mathrm{ppm})$. However, the presence of discharges assisted the catalysts in removing $80 \mathrm{ppm}$ of $\mathrm{CO}$. Maximum removal of THC was achieved by $\mathrm{CuO}$ packed PACR followed by $\mathrm{Fe}_{2} \mathrm{O}_{3}$ and $\mathrm{Pd} / \mathrm{Al}_{2} \mathrm{O}_{3}$ packed PACR. In this case too, the pulsed discharges assisted the catalysts in removing the hydrocarbons.

The above results show that even at room temperature some reactions were taking place on the surface of the catalyst in presence of pulsed discharges, which resulted in the removal of NOx, CO and THC. Though the removal efficiencies of $\mathrm{CO}$ and THC are low in these studies (Table 2), it is still quite interesting considering the fact that the catalysts are not active at room temperature.

\subsection{STUDIES USING A COMBINATION OF PLASMA/CATALYTIC REACTORS}

In this study, the exhaust gas from the diesel engine is made to pass through a combination of catalytic and plasma reactors connected in series. This is an attempt to study the feasibility of placing a plasma reactor along the exhaust channel in a vehicle without disturbing the existing catalytic converters. Both conventional and non-conventional catalysts were used in the form of pellets as well as a honeycomb structure. Initial studies were focused on selecting a suitable combination of PR and CR. For this, catalytic reactor packed with $\mathrm{Pd} / \mathrm{Al}_{2} \mathrm{O}_{3}$ pellets was tested for two combinations with $\mathrm{PR}$. In the first case, $\mathrm{CR}$ was put after PR (this combination is referred as $P R+C R$ ) and in the next case CR was put before PR (this combination is referred as $C R+P R$ ). The studies were carried out at different temperatures of CR. It should be noted that in all these experiments the PR was kept at room temperature and only the temperature of the $\mathrm{CR}$ was raised. Preliminary results in regard to this were presented in [16]. Fig. 6a shows the NOx removal efficiencies for PR +CR combination at different temperatures. At room temperature and at $100^{\circ} \mathrm{C}$, the catalytic adsorption is high resulting in the high NOx removal efficiencies. The NOx removal efficiency decreases with increase in the temperature of the catalytic reactor. The NOx removal efficiency was as low as $35 \%$ when the temperature of $\mathrm{CR}$ is raised 


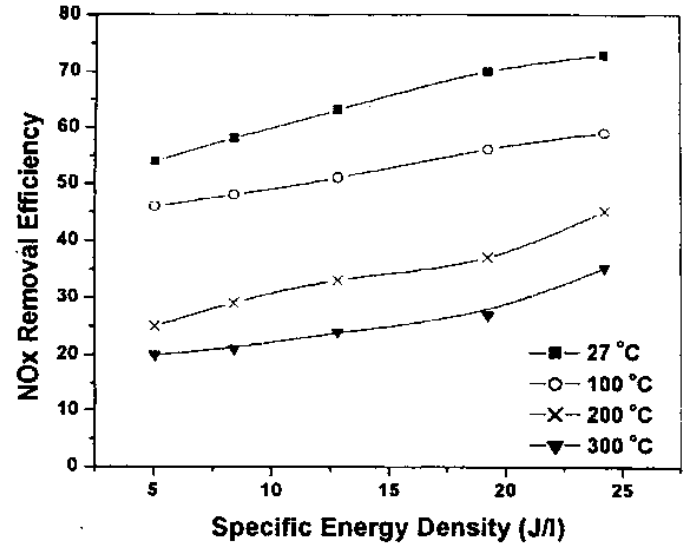

(a)

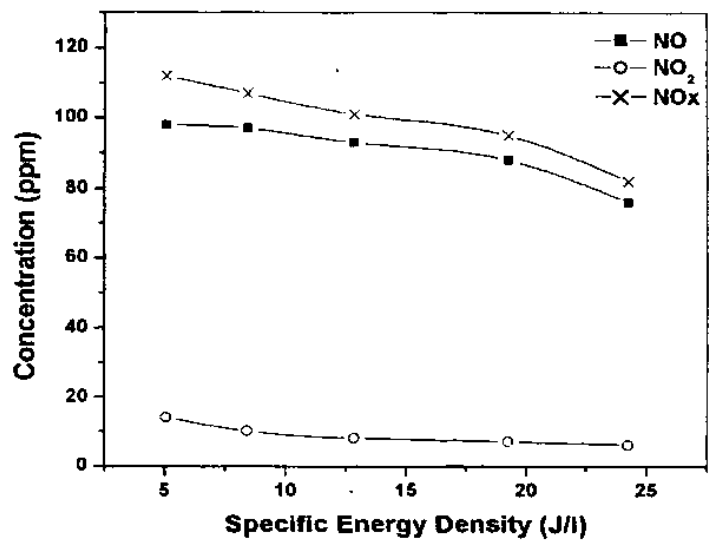

(b)

Figure 6. a, NOx removal efficiencies for $\mathrm{PR}+\mathrm{CR}\left(\mathrm{Pd} / \mathrm{Al}_{2} \mathrm{O}_{3}\right)$ combination at different temperatures; $b$, concentrations of $\mathrm{NO}, \mathrm{NO}_{2}$ and $\mathrm{NOx}$ for $\mathrm{PR}+\mathrm{CR}\left(\mathrm{Pd} / \mathrm{Al}_{2} \mathrm{O}_{3}\right)$ combination at $200^{\circ} \mathrm{C}$.

to $300^{\circ} \mathrm{C}$. This was because the $\mathrm{NO}_{2}$ generated by $\mathrm{PR}$ was adsorbed on the catalyst surface initially and slowly dissociated back into NO. This was evident as high concentration of NO was still left after the treatment with $\mathrm{PR}+\mathrm{CR}$ combination. Figure $6 \mathrm{~b}$ shows the concentrations of NO, $\mathrm{NO}_{2}$ and $\mathrm{NOx}$ as function of specific energy density at $200^{\circ} \mathrm{C}$ with $\mathrm{PR}+\mathrm{CR}$ combination. It is observed that the concentration of $\mathrm{NO}_{2}$ was very low indicating the adsorption by catalyst whereas that of NO was high. This clearly showed that some of the $\mathrm{NO}_{2}$ adsorbed on the catalyst was slowly dissociated into NO.

For CR + PR combination, it is found that at all temperatures the NOx removal efficiency is very high when compared to that of PR + CR combination. For example, Fig. 7a compares the removal efficiencies of NOx, for both the combinations, at $200^{\circ} \mathrm{C}$ and at $300^{\circ} \mathrm{C}$. At $200^{\circ} \mathrm{C}$, NOx removal efficiency for $\mathrm{CR}+\mathrm{PR}$ combination was about $40 \%$ higher than that of $\mathrm{PR}+\mathrm{CR}$ combination and at

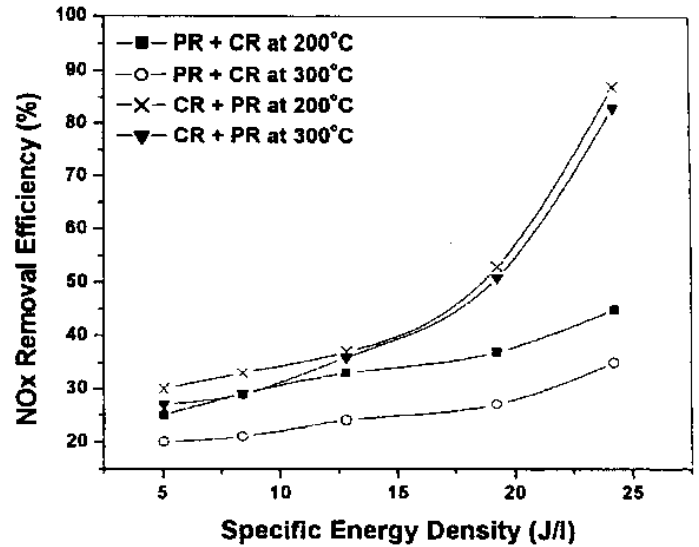

(a)

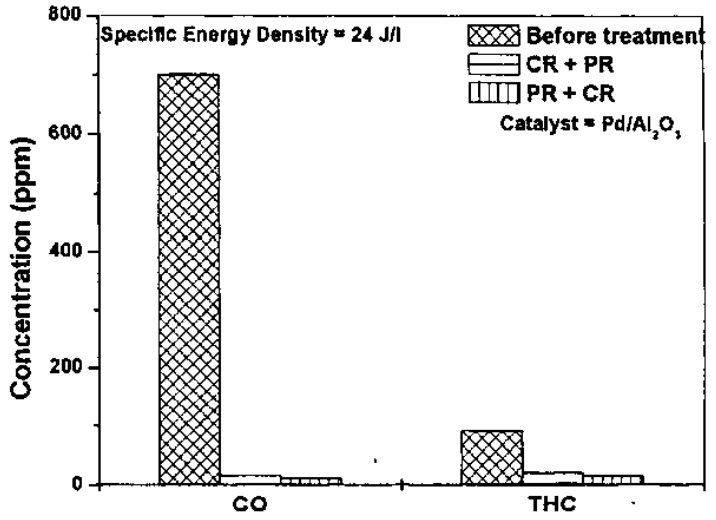

(b)

Figure 7. a, comparison of NOx removal efficiencies of $\mathrm{PR}+\mathrm{CR}$ and $\mathrm{CR}+\mathrm{PR}$ combinations (catalyst $-\mathrm{Pd} / \mathrm{Al}_{2} \mathrm{O}_{3}$ ) at $200^{\circ} \mathrm{C}$ and $300^{\circ} \mathrm{C}$; $\mathrm{b}$, comparison of concentrations of $\mathrm{CO}$ and THC before and after treatment for both $\mathrm{PR}+\mathrm{CR}$ and $\mathrm{CR}+\mathrm{PR}$ combinations at $300^{\circ} \mathrm{C}$.

$300^{\circ} \mathrm{C}$, the difference was about $50 \%$. The $\mathrm{N}_{2} \mathrm{O}$ concentrations were monitored for both the combinations. There was only negligible increase in the concentration of $\mathrm{N}_{2} \mathrm{O}$ in both the combinations.

Figure $7 \mathrm{~b}$ compares the concentrations of $\mathrm{CO}$ and THC before and after treatment for both the combinations at $300^{\circ} \mathrm{C}$. The performance of both the combinations was equally good with respect to $\mathrm{CO}$ and THC removal and there is only a negligible difference between the two.

It should be noted here that the above set of experiments were conducted with only one catalyst $\left(\mathrm{Pd} / \mathrm{Al}_{2} \mathrm{O}_{3}\right)$ in the $\mathrm{CR}$ but for two combinations, $\mathrm{CR}+\mathrm{PR}$ and $\mathrm{PR}+$ $\mathrm{CR}$. It is inferred that the $\mathrm{CR}+\mathrm{PR}$ combination performs better in NOx removal and henceforth the studies were reported for CR + PR combination. The advantages of using $\mathrm{CR}+\mathrm{PR}$ combination include preventing the deposition of $\mathrm{HNO}_{3}$ formed by PR on the catalysts (as observed 


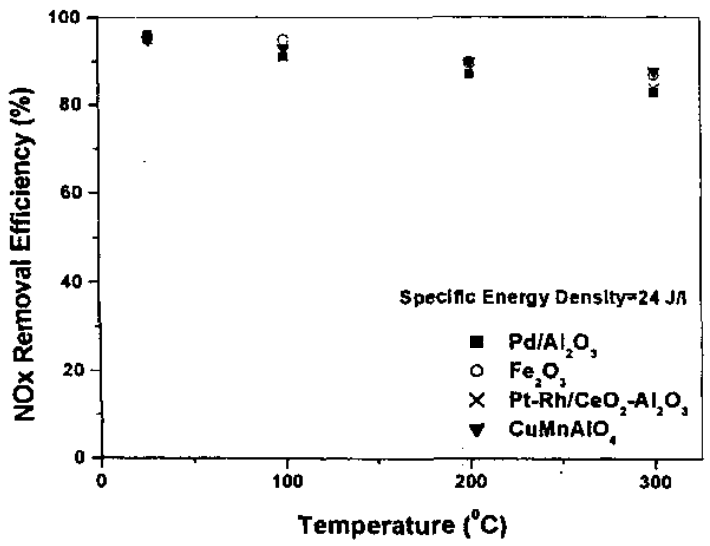

Figure 8. NOx removal efficiency for $C R+P R$ combination using different catalysts as a function of temperature.

under PR + CR case) and achieving maximum NOx removal efficiency for a given temperature of the CR. Further experiments were carried out using the $C R+P R$ combination.

Figure 8 shows the NOx removal efficiencies as a function of temperature of CR for CR + PR combination employing all the four catalysts. It can be observed that as temperature increases the removal efficiency decreases. At room temperature the $\mathrm{NOx}$ removal was $96 \%$ and at $300^{\circ} \mathrm{C}$, it was $83 \%$ for $\mathrm{Pd} / \mathrm{Al}_{2} \mathrm{O}_{3}$ catalysts. This is because at room temperature the catalytic adsorption aids the $\mathrm{NOx}$ removal. At $300^{\circ} \mathrm{C}$, most of the $\mathrm{NO}$ was oxidized to $\mathrm{NO}_{2}$ and reduction in total NOx concentration was reduced. However, this decrease is not very high and NOx removal efficiency is always above $80 \%$. Hence, NOx can be removed effectively irrespective of the temperature of the catalytic reactor. All the catalysts showed maximum removal of $\mathrm{CO}$ and $\mathrm{THC}$ at $200^{\circ} \mathrm{C}$ and $300^{\circ} \mathrm{C}$. This is because the catalysts become active only above a temperature of $200^{\circ} \mathrm{C}$.

\subsubsection{STUDIES WITH CR + PR COMBINATION (CR CONSISTS OF CATALYSTS IN THE FORM OF PELLETS)}

Two kinds of catalysts were used here, $\mathrm{Pd} / \mathrm{Al}_{2} \mathrm{O}_{3}$ (conventional) and $\mathrm{Fe}_{2} \mathrm{O}_{3}$ (non-conventional) in the pellet form. The performances of both the catalysts were studied in combination with PR. Figure 9a shows the NOx removal efficiencies achieved using these catalysts in $\mathrm{CR}+$ $\mathrm{PR}$ combination when $\mathrm{CR}$ is maintained at $300^{\circ} \mathrm{C}$. The catalysts alone did not remove much NOx. For example, $\mathrm{Pd} / \mathrm{Al}_{2} \mathrm{O}_{3}$ could remove only $35 \mathrm{ppm}$ of NOx (about 20\%) and $\mathrm{Fe}_{2} \mathrm{O}_{3}$ could remove only $15 \mathrm{ppm}$ of $\mathrm{NOx}$ (about 10\%) even at $300^{\circ} \mathrm{C}$ in the absence of discharge plasma. This is because at high oxygen atmosphere like diesel exhausts the catalysts oxidize most of the $\mathrm{NO}$ into $\mathrm{NO}_{2}$ keeping NOx constant. But when $C R$ is combined with $P R$, the

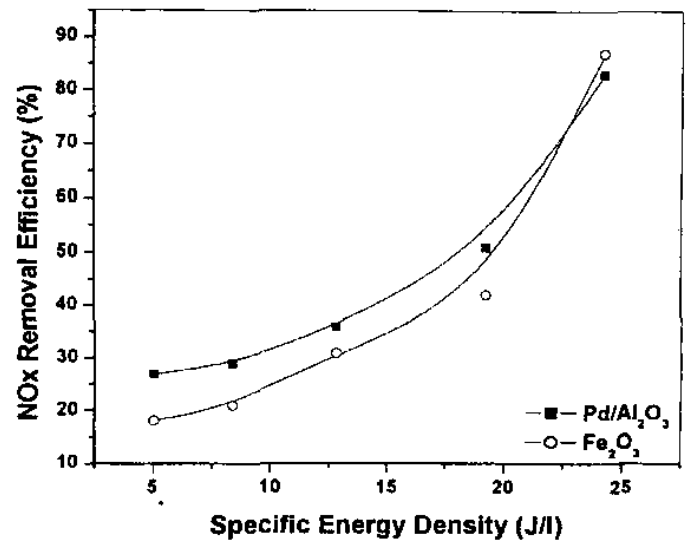

(a)

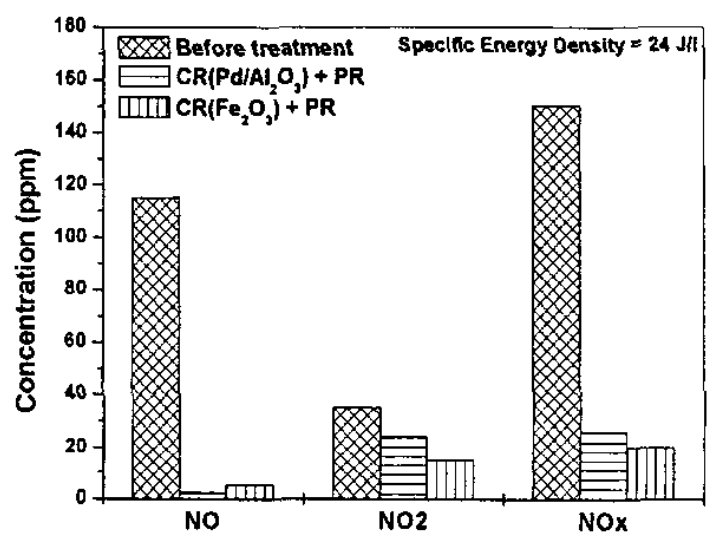

(b)

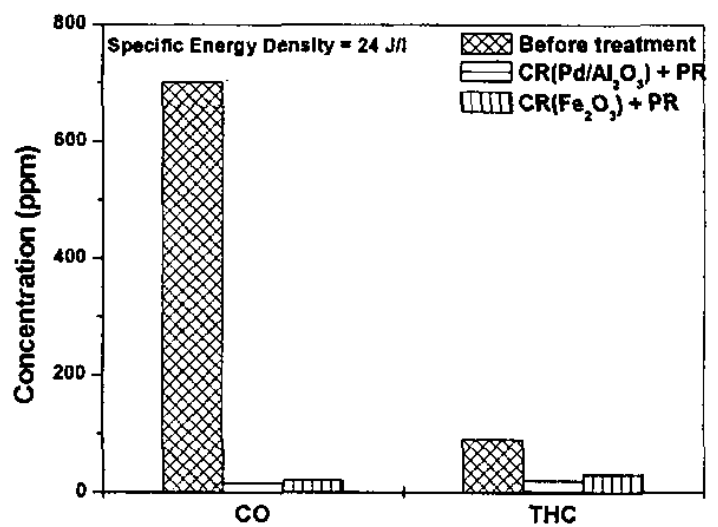

(c)

Figure 9. a, NOx removal efficiencies for $\mathrm{CR}+\mathrm{PR}$ combination at $300^{\circ} \mathrm{C}$ (catalysts in the form of pellets); $b$, comparison of concentrations of NO, $\mathrm{NO}_{2}$ and $\mathrm{NOx}$ before and after treatment for CR + PR combination at $300^{\circ} \mathrm{C}$ (catalysts in the form of pellets); c, comparison of concentrations of $\mathrm{CO}$ and THC before and after treatment for $\mathrm{CR}+\mathrm{PR}$ combination at $300^{\circ} \mathrm{C}$ (catalysts in the form of pellets).

NOx removal efficiencies increased to $83 \%$. Here the NOx removal was because of the presence of $\mathrm{PR}$, the processes of which have already been explained. With $\mathrm{Fe}_{2} \mathrm{O}_{3}$ pellets 
inside the $\mathrm{CR}$ the $\mathrm{NOx}$ removal efficiency was slightly higher than that with $\mathrm{Pd} / \mathrm{Al}_{2} \mathrm{O}_{3}$. However, at lower specific energy densities $\mathrm{Pd} / \mathrm{Al}_{2} \mathrm{O}_{3}$ showed better performance. The $\mathrm{N}_{2} \mathrm{O}$ production was very low with both the catalysts. Figure $9 \mathrm{~b}$ shows the concentrations of $\mathrm{NO}, \mathrm{NO}_{2}$ and $\mathrm{NOx}$ before and after treatment using $\mathrm{Pd} / \mathrm{Al}_{2} \mathrm{O}_{3}$ and $\mathrm{Fe}_{2} \mathrm{O}_{3}$ catalysts in $\mathrm{CR}+\mathrm{PR}$ combination when $\mathrm{CR}$ is maintained at $300^{\circ} \mathrm{C}$.

Figure $9 \mathrm{c}$ shows the concentrations of $\mathrm{CO}$ and $\mathrm{THC}$ before and after treatment using $\mathrm{Pd} / \mathrm{Al}_{2} \mathrm{O}_{3}$ and $\mathrm{Fe}_{2} \mathrm{O}_{3}$ catalysts in $\mathrm{CR}+\mathrm{PR}$ combination when $\mathrm{CR}$ is maintained at $300^{\circ} \mathrm{C}$. With catalysts alone, $\mathrm{CO}$ was almost completely removed for $\mathrm{Pd} / \mathrm{Al}_{2} \mathrm{O}_{3}$ but when $\mathrm{PR}$ is placed after $\mathrm{CR}$ the $\mathrm{CO}$ concentration was slightly increased. This is because of $\mathrm{CO}_{2}$ being reduced to $\mathrm{CO}$ and $\mathrm{O}_{2}$ in presence of pulsed discharges in the PR. It is also true that partial oxidation of $\mathrm{HC}$ species will result in $\mathrm{CO}$ production. However, this increase is very negligible $(15-20 \mathrm{ppm})$ and since diesel engines emit lesser $\mathrm{CO}$ concentration this increase should not be a problem. The same is observed with $\mathrm{Fe}_{2} \mathrm{O}_{3}$ catalyst also. Both the catalysts were found to be equally good in removing $\mathrm{CO}$ and $\mathrm{THC}$ when combined with a plasma reactor. It is inferred from these experiments that the catalyst $\mathrm{Fe}_{2} \mathrm{O}_{3}$ was found to be as good as conventional catalyst $\mathrm{Pd} / \mathrm{Al}_{2} \mathrm{O}_{3}$ in the removal of $\mathrm{CO}$ and $\mathrm{THC}$.

\subsubsection{STUDIES WITH CR + PR COMBINATION (CR CONSISTS OF CATALYSTS IN HONEYCOMB STRUCTURE)}

Current catalytic converters employ catalysts coated on a honeycomb structure for treating auto exhausts. We have conducted experiments with a section of one such honeycomb structure (Bharat Heavy Electricals Limited, India make) and coating the same with a conventional as well as a non-conventional catalyst. The honeycomb structure was then placed inside a glass tube forming a catalytic reactor. The plasma reactor was placed after this catalytic reactor and the details of the studies are as reported below. A commonly used conventional catalyst such as Pt$\mathrm{Rh} / \mathrm{CeO}_{2}-\mathrm{Al}_{2} \mathrm{O}_{3}$ and a new, laboratory made non-conventional catalyst $\mathrm{CuMnAlO}$, were used for coating on the cordierite honeycomb structure. Fig. 10a shows the NOx removal efficiencies with these catalysts in CR + PR combination when $\mathrm{CR}$ is maintained at $300^{\circ} \mathrm{C}$. The catalysts alone could not remove significant amount of NOx. Both the catalysts removed only $30 \mathrm{ppm}$ of NOx out of total 150 ppm in the absence of pulsed discharges, which amounts to $20 \%$ of NOx removal. However, when PR is placed after CR more than $85 \%$ of the NOx was removed in the combined process with both the catalysts. Fig. 10b shows the concentrations of $\mathrm{NO}, \mathrm{NO}_{2}$ and $\mathrm{NOx}$ before and after treatment for $\mathrm{CR}+\mathrm{PR}$ combination when $\mathrm{CR}$ is maintained at $300^{\circ} \mathrm{C}$. The $\mathrm{N}_{2} \mathrm{O}$ production was low in both the cases.
Figure 10c shows the concentrations of $\mathrm{CO}$ and THC before and after treatment using these two catalysts in $\mathrm{CR}$ $+\mathrm{PR}$ combination when $\mathrm{CR}$ is maintained at $300^{\circ} \mathrm{C}$. Catalysts alone oxidized $\mathrm{CO}$ to $\mathrm{CO}_{2}$ to a maximum extent (nearly $100 \%$ ) and the increase in CO (due to dissociation of $\mathrm{CO}_{2}$ ) concentration because of PR was negligible. THC was also removed effectively by both the catalysts. It is observed from the above set of experiments that the new, laboratory made catalyst $\mathrm{CuMnAlO}$ performed equally effective when compared to the conventional expensive catalyst. The new catalyst is also inexpensive though the exact cost per gram is yet to be evaluated. This laboratory made catalyst appears to be a promising alternative to the conventional catalyst.

\subsection{RELATIVE PERFORMANCE OF THE REACTORS USED IN CURRENT STUDY}

In this section, the results obtained by using different reactors are compared. In each kind of reactor, the best one was selected. Since not all the reactors were studied under different temperature conditions, only room temperature studies are compared. In the first reactor i.e. PR, $\mathrm{PR}$ without pellets was found to be better as compared to PR packed with dielectric pellets. In the second kind of reactor i.e. $\mathrm{PACR}, \mathrm{Fe}_{2} \mathrm{O}_{3}$ catalyst showed better performance than $\mathrm{CuO}$ and $\mathrm{Fe}_{2} \mathrm{O}_{3}$. In the third reactor configuration, $\mathrm{CR}+\mathrm{PR}, \mathrm{Pd} / \mathrm{Al}_{2} \mathrm{O}_{3}$ (pellets) and $\mathrm{CuMnAlO}$ (coated on honeycomb structure) catalysts were proved to be better. All the above reactors were selected by taking into account the removal efficiencies of $\mathrm{NOx}, \mathrm{CO}$ and THC. Fig. 11a shows NOx removal efficiencies for all these reactors at room temperature. PACR packed with $\mathrm{Fe}_{2} \mathrm{O}_{3}$ and $\mathrm{CR}+\mathrm{PR}$ employing $\mathrm{Pd} / \mathrm{Al}_{2} \mathrm{O}_{3}$ catalyst showed maximum removal efficiencies even at lower specific energy densities. This is because of high adsorption characteristic nature of these catalyst pellets at room temperature. $\mathrm{CuMnAlO}_{4}$ also exhibited adsorption characteristics at room temperature but it was not as high as that of $\mathrm{Fe}_{2} \mathrm{O}_{3}$ as the catalyst is coated onto a honeycomb structure. The NOx removal efficiency was $76 \%$ for PR without pellets and is less than that of the other reactors at room temperature.

Figure $11 \mathrm{~b}$ shows the concentrations of $\mathrm{CO}$ and THC before and after treatment for all the reactors at room temperature. There was no change in initial concentration of $\mathrm{CO}$ for PR without pellets and $\mathrm{CR}\left(\mathrm{CuMnAlO}_{4}\right)+\mathrm{PR}$ reactors after the treatment. PACR packed with $\mathrm{Fe}_{2} \mathrm{O}_{3}$ could remove about $150 \mathrm{ppm}$ of $\mathrm{CO}$ at room temperature itself. This is an important result as catalysts seldom work at room temperatures. With the reactor $\mathrm{CR}\left(\mathrm{Pd} / \mathrm{Al}_{2} \mathrm{O}_{3}\right)+$ $\mathrm{PR}$, there was a small increase in the $\mathrm{CO}(10 \mathrm{ppm})$ concentration from initial concentration. Though the catalyst adsorbed about $10 \mathrm{ppm}$ of $\mathrm{CO}$ the PR placed after CR reduced $\mathrm{CO}_{2}$ into $\mathrm{CO}$. However, the increase is very small and can be ignored. The removal of THC is more with 


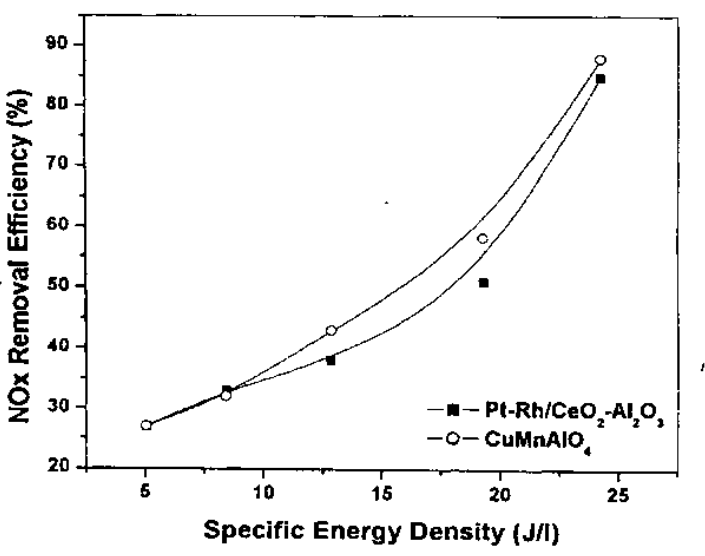

(a)

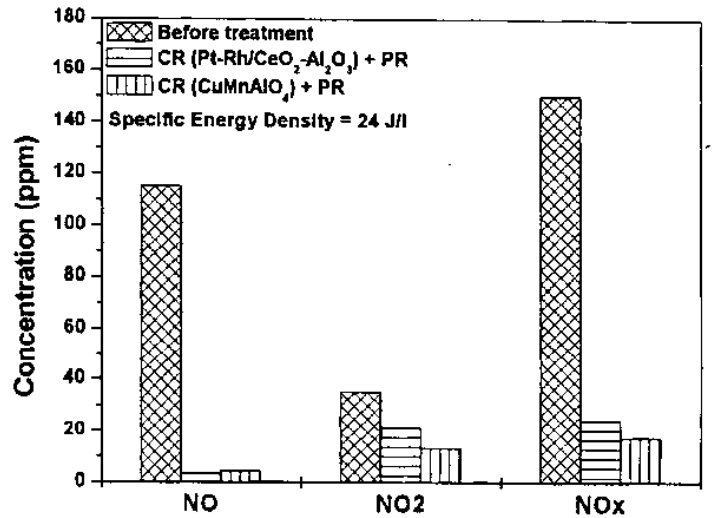

(b)

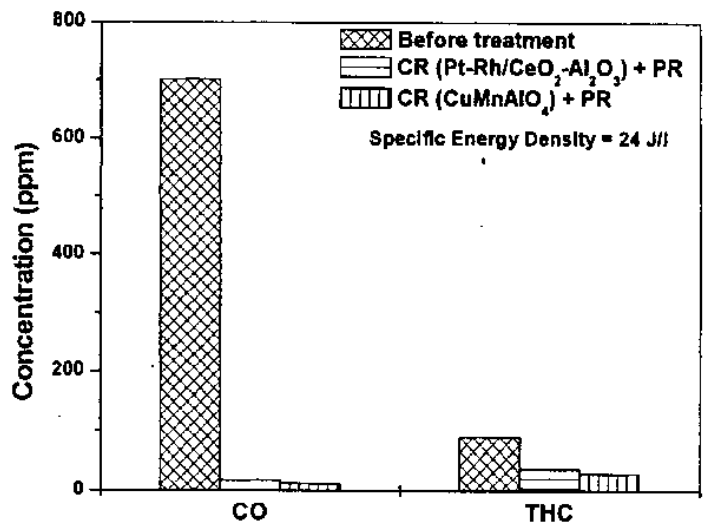

(c)

Figure 10. a, NOx removal efficiencies for $\mathrm{CR}+\mathrm{PR}$ combination at $300^{\circ} \mathrm{C}$ (catalysts in the form of honeycomb); b, comparison of concentrations of NO, $\mathrm{NO}_{2}$ and NOx before and after treatment for $\mathrm{CR}+$ $\mathrm{PR}$ combination at $300^{\circ} \mathrm{C}$ (catalysts in the form of honeycomb); $\mathrm{c}$, comparison of concentrations of $\mathrm{CO}$ and $\mathrm{THC}$ before and after treatment for $\mathrm{CR}+\mathrm{PR}$ combination at $300^{\circ} \mathrm{C}$ (catalysts in the form of honeycomb).

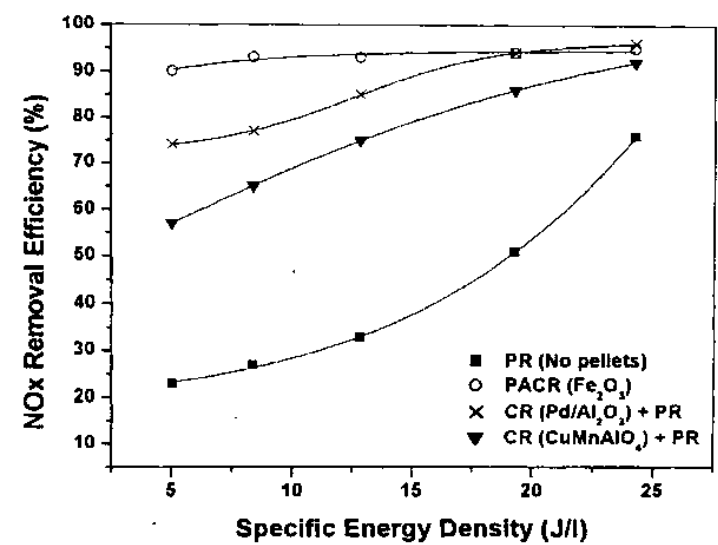

(a)

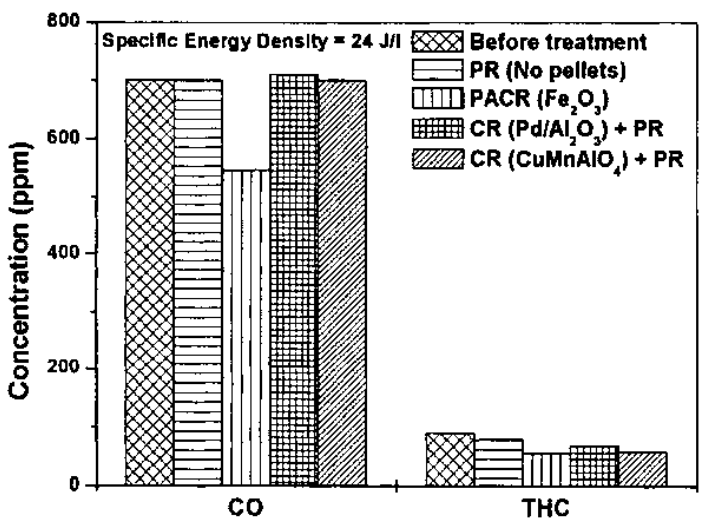

(b)

Figure 11. a, NOx removal efficiencies for different reactors at room temperature as a function of specific energy density; b, concentrations of $\mathrm{CO}$ and THC before and after treatment for different reactors at room temperature.

PACR packed with $\mathrm{Fe}_{2} \mathrm{O}_{3}$ and other reactors showed moderate performance. PR without pellets showed the least removal of THC.

\section{CONCLUSIONS}

$\mathrm{T}_{\mathrm{ar}}^{\mathrm{H}}$

1. The room temperature studies of plasma reactor (PR) packed with and without dielectric pellets showed that the NOx removal efficiency is higher for PR without pellets. Furthermore, when the exhaust gas was treated with a PR packed with $\mathrm{BaTiO}_{3}$ pellets, an increase in $\mathrm{CO}$ was observed as well as the formation of higher levels of $\mathrm{N}_{2} \mathrm{O}$.

2. The performance of plasma-assisted catalytic reactor (PACR), where plasma and catalyst are in the same reactor, showed that even at room temperature some reactions were taking place on the surface of the catalyst in presence of pulsed discharges resulting in the removal of 
NOx, CO and THC. Though the removal efficiencies of $\mathrm{CO}$ and THC are not high in these studies, it is still quite interesting considering the fact that the catalysts are not active at room temperature.

3. $C R+P R$ combination was found to be better than $\mathrm{PR}+\mathrm{CR}$ combination. For CR + PR combination the NOx removal efficiency was always high irrespective of the temperature of the CR.

4. In the absence of plasma the catalyst could remove NOx only up to about $15-20 \%$ even at $300^{\circ} \mathrm{C}$. However, in presence of plasma the NOx removal efficiency was always higher than $80 \%$ for temperatures up to $300^{\circ} \mathrm{C}$.

5. The studies conducted using a new, lab-made, less expensive catalyst $\left.(\mathrm{CuMnAlO})_{4}\right)$ used in conjunction with pulsed discharge showed promising results. Interestingly, the new catalyst performed equally well in the removal of NOx, CO and THC from the diesel engine exhaust when compared to that with conventional three-way catalyst.

\section{ACKNOWLEDGMENTS}

We thank the Department of Solid State and Structural Chemistry Unit, IISc and Bharat Heavy Electricals Limited, Bangalore, for providing some of the catalysts during the course of our experiments.

\section{REFERENCES}

[1] S. Masuda, and H. Nakao, "Control of NOx by Positive and Negative pulsed Corona Discharges”, IEEE Trans. IA, Vol. 26, pp. 374-383, 1990.

[2] G. Dinelli, L. Civitano, and M. Rea, "Industrial Experiments on Pulse Corona Simultaneous Removal of $\mathrm{NOx}$ and $\mathrm{SO}_{2}$ from Flue Gas", IEEE Trans. IA, Vol. 26, pp. 535-541, 1990.

[3] J. S. Chang, P. A. Lawless, and T. Yamamoto, "Corona Discharge Processes", IEEE Trans. Plasma Science, Vol. 19, No. 6, pp. 1152-1166, 1991.

[4] G. E. Vogtlin, and B. M. Penctrante, "Pulsed Corona Discharge for Removal of NOx from Flue Gas", NATO ASI Series 34. Oxford, U.K: Springer-Verlag, 1993, Part.B, pp. 187-198.

[5] Y. S. Mok and I. S. Nam, "Positive Pulsed Corona Discharge Process for Simultaneous Removal of $\mathrm{SO}_{2}$ and NOx from IronOre Sintering Flue Gas", IEEE Trans. Plasma Science, Vol. 27, pp. 1188-1196, 1999.

[6] T. Oda, T. Kato, T. Takahashi, and K. Shimizu, "Nitric Oxide Decomposition in Air by Using Non-thermal Plasma Processing
With Additives and Catalyst", IEEE IAS Annual Meeting. pp. 1803-1807, 1996.

[7] K. Shimizu and T. Oda, "DeNOx Process in Flue Gas Combined With Non-thermal Plasma and Catalyst", IEEE-IAS Annual Mecting, pp. 1942-1949, 1997.

[8] K. Shimizu, T. Hirano, and T. Oda, "Effect of Water Vapor and Hydrocarbons in Removing NOx by Using Nonthermal Plasma and Catalyst", IEEE Trans. IA, Vol. 37, pp. 464-471, 2001.

[9] A. Mizuno, K. Shimizu, K. Yanagihara, K. Kinoshita, K. Tsunoda, H. H. Kim, and S. Katsura, "Effect of Additives and Catalysts on Removal of Nitrogen Oxides Using Pulsed Discharge", IEEE IAS Annual Meeting, pp. 1806-1812, 1996.

[10] H. H. Kim, K. Takashima, S. Katsura, and A. Mizuno, "Lowtemperature NOx Reduction Processes Using Combined Systems of Pulsed Corona Discharge and Catalysts", J. Phys. D Appl. Phys. Vol. 34, pp. 604-613, 2001.

[11] T. Yamamoto, C. L. Yang, M. R. Beltran, and Z. Kravets, "Plasma Assisted Chemical Process for NOx Control", IEEE Trans. IAS, Vol. 36, pp. 923-927, 2000.

[12] M. G. Grothaus, and E. R. Fanick, "Investigations of a Pulsed Corona Reactor for Heavy Duty Diesel Engine Emissions Reduction", Proceedings 23rd International Power Modulation Symposium, pp. 20-23, Rancho Mirage, CA, 1998.

[13] M. G. Grothaus, M. K. Khair, and P. Paul, "A Synergistic Approach for the Removal of NOx and PM From Diesel Engine Exhaust", 12th IEEE International Pulsed Power Conference, Digest of Technical Papers, Vol. 1, pp. 506-510, 1999.

[14] B. M. Penentrate, M. C. Hsio, B. T. Merrit, G. E. Vogtlin, and P. H. Wallman, "Comparison of Electrical Discharge Techniques for Non-thermal Plasma Processing of $\mathrm{NO}$ in $\mathrm{N}_{2}$ ", IEEE Trans. Plasma Science, Vol., 23, pp. 679-687, 1995.

[15] B. S. Rajanikanth, and S. Rout, "Studies on Nitric Oxide Removal in Simulated Gas Compositions Under Plasma-Dielec. tric/Catalytic Discharges", Fuel Processing Technology, Elsevier, Vol. 74, pp 177-195, 2001.

[16] B. S. Rajanikanth, and V. Ravi, "Removal of NOx from Dicscl Engine Exhaust Using Pulsed Electrical Discharge Coupled with a Catalytic Converter", 12th International Symposium on High Voltage Engineering, India, Vol. 5, pp. 1283-1286, 2001.

[17] K. Yan, S. Kanazawa, T. Ohkubo, and Y. Nomoto, "Oxidation and Reduction Processes During NOx Removal in $\mathrm{N}_{2}+\mathrm{O}_{2}$ with Corona Induced Non-thermal Plasma", Proceedings, ICESP VII, KOREA, 1998. 